\title{
A case report on ruptured rudimentary horn ectopic pregnancy
}

\author{
Milan R. Shingala*, Bhavesh B. Airao
}

Department of Obstetrics and Gynecology. CUSMCH, Surendranagar, Gujarat, India

Received: 17 March 2021

Revised: 14 May 2021

Accepted: 15 May 2021

\section{*Correspondence:}

Dr. Milan R. Shingala,

E-mail: drmilanpate19437@gmail.com

Copyright: ( $)$ the author(s), publisher and licensee Medip Academy. This is an open-access article distributed under the terms of the Creative Commons Attribution Non-Commercial License, which permits unrestricted non-commercial use, distribution, and reproduction in any medium, provided the original work is properly cited.

\begin{abstract}
Unicornuate uterus with noncommunicating rudimentary horn occurs due to incomplete fusion of mullerian ducts. This malformation results from the defective fusion of the duct with the contra-lateral side. This rudimentary horn may or may not have functional cavity. Pregnancy in this horn is a rare phenomenon usually resulting in rupture during second trimester of pregnancy. IT is a rare condition that can lead to a catastrophic outcome when it rupture. Prerupture diagnosis of pregnancy in rudimentary horn with ultrasonography is technically difficult, with sensitivity of $30 \%$. Pregnant rudimentary horn can present with wide range of symptoms that may be similar to ectopic pregnancy or may remain silent with features of normal pregnancy.1-2 We report a case of ruptured non-communicating rudimentary horn at 19 weeks in pregnant lady. In our opinion, routine excision of rudimentary horn should be undertaken during nonpregnant state laparoscopically. However, those women who refuse should be adequately counselled regarding potential complications and if pregnancy occurs in rudimentary horn, first trimester laparoscopic excision should be done.
\end{abstract}

Keywords: Mullerian duct malformation, Ruptured rudimentary horn pregnancy, Unicornuate uterus

\section{INTRODUCTION}

Ruptured rudimentary horn is a life-threatening obstetrical emergency encountered frequently in the emergency department where the diagnosis is either missed or delayed. Unicornuate uterus with a rudimentary horn is a rare mullerian anomaly that has a high incidence of obstetric complications that include ectopic pregnancy in the rudimentary horn. Unicornuate uterus results from abnormal development and fusion of the mullerian ducts usually associated with various degrees of rudimentary horn which may be communicating or non-communicating with the uterine cavity. Pregnancy in noncommunicating rudimentary horn is possible by trans-peritoneal migration of sperm or fertilized ovum. ${ }^{3-4}$ It occurs in approximately 1 of every 76,000 pregnancies. The risk of uterine rupture is $50-90 \%$, with most ruptures (approximately 80\%) occurring by the end of the second trimester. ${ }^{1,2}$
The final result is the development of an accessory horn which may have a functional cavity, or it may simply be a small solid mass of the uterine muscle with no functional endometrium. $^{5}$ The majority of the cases remain undiagnosed unless a pregnancy develops in the accessory horn, and most of these patients present when the rupture has already occurred. A diagnosis of this anomaly is usually confirmed intraoperatively.

\section{CASE REPORT}

A 20-year-old woman gravida 2, para 0 , abortion 1 came to emergency with severe lower pain abdomen and vomiting since last one day. She was 18 weeks 4days pregnant. The patient had no significant medical or surgical history. On examination patient was in hypovolemic shock with moderate pallor, hypotension, and tachycardia. 
The abdomen was tense and symphysiofundal height was 22 weeks. Her bowel sounds were normal. On pelvic examination cervix and vagina were healthy, there was no bleeding through os, and size of uterus could not be made out due to intense tenderness. Per rectal examination was within normal limits. Immediately two large bore intravenous canula were inserted, one liter of fluid was rushed, patient was catheterized (she passed $100 \mathrm{~mL}$ of clear urine), and urgent investigations and cross match was sent. urgent ultrasound was done. Extra uterine fetus without fetal movements and cardiac activity noted in left lumbar leasion with maturity of 18 weeks and 4 days.

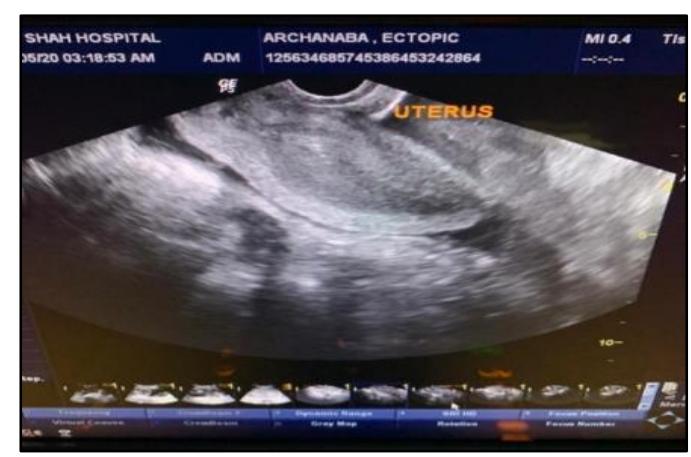

Figure 1: Empty uterus on trans vaginal sonography.

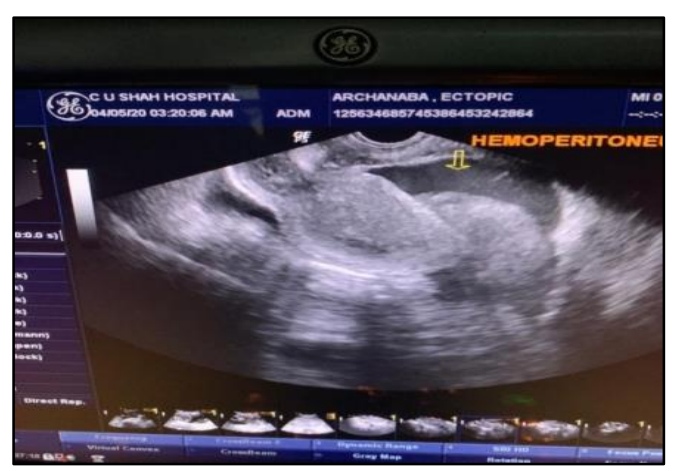

Figure 2: Moderate hemoperitonium with empty uterine cavity.

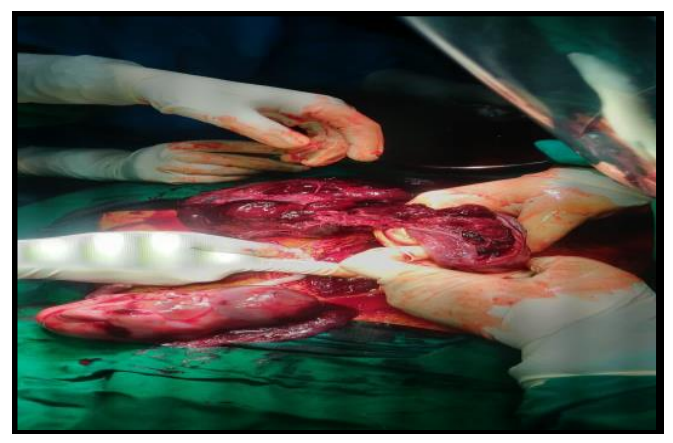

Figure 3: Intra operative picture of ruptured rudimentary horn with dead fetous.

E/o moderate echogenic free fluid with echogenic material measuring $9.9 \times 6.9 \mathrm{~cm}$ noted in peritoneal cavity s/o Hemoperitoneum Left adrenexa could not be visualised separately due to mod hemoperitoneum. Uterus appear mildly bulky with decidual reaction Her hemoglobin was $6.5 \mathrm{~g} \%$, one unit blood was rushed. Her Beta HCG report was 70880.Immediately The patient was taken for explorative laparotomy. Intraoperatively a unicornuate uterus with rupture of noncommunicating rudimentary horn was confirmed and a dead fetus was found in peritoneal cavity with moderate hemoperitoneum. Both the ovaries and tubes were normal. Placenta was found separated in abdominal cavity. Excision of rudimentary horn, ipsilateral salpingectomy was done. Patient received three units of blood transfusion. She had an uneventful recovery and was discharged on day 7 post operative with an advice for hysterosalpingogram 6 weeks later. On her histopathological report, Specimen labelled as rudimentary horn shows uterine myometrium and endometrium consistent with uterine structure. Specimen also shows placental tissue with hemorrhage.

\section{DISCUSSION}

Mechanism of pregnancy occurrence in the noncommunicating rudimentary horn is assumed to be byFirst theory describes the retrograde entry of sperm into the fallopian tube of the rudimentary horn. This would require sperm to navigate through the unicornuate uterus, the ipsilateral tube, and peritoneal cavity before entry into the rudimentary side. The second theory proposed by Latto and Norman in 1950 states that microscopic channels may exist between the endometrial and rudimentary horn cavity. ${ }^{6,7}$ These would allow direct passage of sperm from the unicornuate cavity to the rudimentary horn.

Patients with unicornuate uterus with a rudimentary horn should be investigated for urinary anomalies; as imaging in some patients revealed an absent kidney on the ipsilateral side pregnancies occur in both communicating and non-communicating horns in proportion to their relative incidence and are equally likely to rupture neonatal mortality is very high as most cases are emergency laparotomy after uterine rupture at premature gestational age. Maternal mortality is low $(0.5 \%)$ but morbidity is very high in view of massive blood loss and morbidly adherent placenta. The natural fate of ectopic pregnancy in rudimentary horn is usually rupture during the last two trimesters due to underdevelopment, variable thickness, and poor distensibility of myometrium and dysfunctional endometrium. ${ }^{7,8}$

The prerupture diagnosis of pregnancy in rudimentary horn has drastically reduced maternal mortality, but the sensitivity of ultrasound to detect pre rupture rudimentary horn pregnancy is very poor (26-30\%), probably because of rarity of the diagnosis and non familiarity of the radiologists about this potentially lethal condition. Early diagnosis before rupture can be managed laparoscopically by immediate excision of the horn, pregnancy, and the ipsilateral fallopian tube., ${ }^{3,4}$ This can be done by Placement of a Foley catheter into the uterine cavity with filled balloon and performing a transabdominal ultrasound scan 
can conclusively exclude an intrauterine pregnancy as it is shown in one case report. ${ }^{11}$ Foley catheter was also used to see whether the horn is communicating with the uterine cavity. ${ }^{10}$ In our case, although the presence of extra uterine pregnancy was confirmed before laparotomy the fact that she sustained a falling accident and the presence of a fetus outside the uterine cavity increased our doubt of uterine rupture..$^{9-11}$ This case further raises the question of whether routine excision of rudimentary horn be undertaken in women with unicornuate uterus as a prophylaxis to prevent such catastrophes.

\section{CONCLUSION}

Despite advances in diagnostic modalities, prenatal diagnosis remains elusive, with confirmatory diagnosis being laparotomy. The diagnosis can be missed in ultrasound especially in inexperienced hands. Precious time may be lost due to delay in diagnosis or misdiagnosis. Timely resuscitation, surgery, and blood transfusion are needed to save the patient. Proper diagnostic methods and early referral from the peripheral hospitals is needed to reduce the morbidity and mortality of the patients. There is a need for an increased awareness of this condition especially in developing countries where the possibility of detection before pregnancy or before the rupture is unlikely, and precious time is lost in shifting these women to the referral hospital.

Funding: No funding sources Conflict of interest: None declared

Ethical approval: Not required

\section{REFERENCES}

1. Johansen K. Pregnancy in a rudimentary horn. Obstet Gynecol. 1983;61:565-7.

2. Daskalakis G, Pilalis A, Lykeridou K, Antsaklis A. Rupture of Noncommunicating Rudimentary Uterine Horn Pregnancy. Obstet Gynecol. 2002;100(5):110801110 .

3. Singhe JY, Rane A, Stalewski H, Gover S .The presentation and early diagnosis of the rudimentary uterine horn. Obstetrics \& Gynecology. 2005; 105:1456-67.

4. Scholtz M. A full-time pregnancy in a rudimentary horn of the uterus. British Journal of Obstetrics \& Gynaecology. 1951;58:293-6.

5. Pal K, Majumdar S, Mukhopadhyay S. Rupture of rudimentary uterine horn pregnancy at 37 weeks gestation with fetal survival. Arch Gynecol Obstet. 2006;274:325-6.

6. Jain R, Gami N, Puri M, Trivedi SS. A rare case of intact rudimentary horn pregnancy presenting as hemoperitoneum. J Hum Reprod Sci. 2010;3:113-5.

7. Lawhon BP, Wax JR, Dufort RT. Rudimentary uterine horn pregnancy diagnosed with magnetic resonance imaging. Obstetrics and Gynecology. 1998;91:869.

8. Leyendecker JR, Gorengaut V, Brown JJ. MR imaging of maternal diseases of the abdomen and pelvis during pregnancy and the immediate postpartum period. Radiographics. 2004;24:1301-16.

9. Smolders D, Deckers F, Pouillon M, Vanderheyden T, Vanderheyden J, De Schepper A. Ectopic pregnancy within a rudimentary horn in a case of unicornuate uterus. Eur Radiol. 2002;12:121-4.

10. Kriplani A, Relan S, Mittal S, Buckshee K. Prerupture diagnosis and management of rudimentary horn pregnancy in the first trimester. Eur J Obstet Gynecol Reprod Biol. 1995;58:203-5.

11. Tsafrir, Rojansky N, Sela HY, Gomori JM. Nadjari M. Rudimentary horn pregnancy: first-trimester prerupture sonographic diagnosis and confirmation by magnetic resonance imaging," Journal of Ultrasound in Medicine. 2005;24(2):219-23.

12. Falcone T, Gidwani G, Paraiso M, Beverly C, Goldberg J. Anatomical variation in the rudimentary horns of a unicornuate uterus: implications for laparoscopic surgery. Hum Reprod. 1997;12:263-5.

Cite this article as: Shingala MR, Airao BB. A case report on ruptured rudimentary horn ectopic pregnancy. Int J Reprod Contracept Obstet Gynecol 2021;10:2504-6. 